\title{
Outcomes of and barriers to cataract surgery in Sao Paulo State, Brazil
}

\author{
Gabriel de Almeida Ferreira, Luisa Fioravanti Schaal, Marcela Dadamos Ferro, Antonio Carlos Lottelli Rodrigues, \\ Rajiv Khandekar and Silvana Artioli Schellini*
}

\begin{abstract}
Background: Cataract is the leading cause of blindness in developing countries and identification of the barriers to accessing treatment is essential for developing appropriate public healthcare interventions. To evaluate the barriers to cataract surgery after diagnosis and assess the postoperative outcomes in Sao Paolo State, Brazil.

Methods: This prospective study evaluated cataract patients from 13 counties in São Paulo State in 2014. Cataract was diagnosed in the community by a mobile ophthalmic unit and patients were referred to a hospital for management. Gender, age, distance to the hospital and local municipal health structure were evaluated as possible barriers. Data were analyzed for postoperative outcomes and the impact on blindness and visual impairment.
\end{abstract}

Results: Six hundred patients were diagnosed with cataract with a mean age of $68.8 \pm 10.3$ years and 374 (62.3\%) were females. Two hundred and fifty-four (42.3\%) patients presented to the referral hospital. One hundred fortyfour (56.7\%) underwent surgery, 56 (22.0\%) decided not to undergo surgery, 40 (15.7\%) required only YAG-Laser and $14(5.5 \%)$ required a spectacle prescription only. Visual acuity increased statistically significantly from 1.07 \pm 0 . $73 \log M A R$ at presentation to $0.25 \pm 0.41 \log M A R$ at the final visit after intraocular lens implantation $(p=0.000)$. There was a statistically significantly decrease from $17(11.8 \%)$ blind patients and 55 (38.2\%) visually impaired patients at presentation to $2(1.4 \%)$ and $5(3.5 \%)$ patients respectively after treatment $(p=0.000)$.

Conclusion: Less than half of the individuals with cataract presented to the hospital for surgery. Among the patients who underwent treatment, there was an overall decrease in the number of blind individuals and visually impaired individuals. The barriers to cataract surgery were older age, greater distance to the hospital, municipalities with fewer inhabitants and less ophthalmic services.

Keywords: Cataract, Blindness, Treatment Outcome, Health services accessibility

\section{Background}

Cataract surgery is a leading cause of blindness in developing countries [1]. In 2010, there were an estimated 39 million blind individuals and 285 million visually impaired individuals globally. Cataract was considered the primary cause of blindness, responsible for $51 \%$ of these cases [2]. In 1990, the World Health Organization (WHO) created "Vision 2020 - the right for sight" initiative, which aims to eliminate avoidable blindness by 2020 worldwide. Despite

\footnotetext{
* Correspondence: sschellini@gmail.com

Universidade Estadual Paulista Julio de Mesquita Filho Faculdade de Medicina Campus de Botucatu Botucatu, Sao Paulo, Brazil
}

improvement in access to surgery, many regions worldwide do have adequate coverage for cataract surgery [3].

Barriers to access cataract surgery differ by regions and include, gender, fear of surgery, status of visual disability, educational level, visual needs, distance from the care provider, cost and lack of an escort/caretaker [4].

Brazil has a universal public health system (Sistema Único de Saúde - SUS) that provides surgery without cost to those in need [5]. Despite universal healthcare, cataract remains the major cause of blindness in Brazil $[6,7]$. Appropriate public healthcare strategies can be developed to eliminate cataract as a source of blindness using data from studies of barriers to cataract surgery in 
regions of Brazil. Currently there are no published studies of barriers to cataract surgery in a Brazilian population. The present study evaluates the barriers to cataract surgery and presents some suggestions to increase the uptake of cataract surgery.

\section{Methods}

A cross-sectional prospective survey was performed in the southwest region of São Paulo State, Brazil, involving patients who were screened at a Ophthalmic Mobile Unit (OMU) in 2014. SUS covered all the costs for treatment. Patients were screened in 13 municipalities (Table 1). The tertiary health reference center for the 13 municipalities was the Clinical Hospital of Botucatu Medical School (Hospital das Clínicas da Faculdade de Medicina de Botucatu - HCFMB). This study was approved by the Ethics Committee of the Faculdade de Medicina de Botucatu - UNESP, Sao Paulo, Brazil and adhered to the tenets of the Declaration of Helsinki. All study subjects signed a consent form.

The UMO team was composed of ophthalmologists and local health workers from each municipality. Subjects underwent a comprehensive ocular exam. Visual acuity (VA) was evaluated using an illuminated Snellen E chart and the values were converted to the logarithm of the minimum angle of resolution (logMAR) for statistical analysis. The Snellen to $\operatorname{logMAR}$ conversion was as follows: counting fingers, hand movement, light perception and without light perception corresponded to 2.10, 2.40, 2.70 and 3.00, respectively [8]. The WHO definitions were used to classify vision as follows: blindness was defined as
$\mathrm{VA}<20 / 400$ and visual impairment was 20/ $400<\mathrm{VA}<20 / 60$ in the better eye with the best optical correction [9].

All participants underwent an objective and subjective refraction with an autorefractor (Accuref-K; Shinn Nippon, Tokyo, Japan) and a manual refractor (RT 6000; Nidek Co. Ltd., Gamagori, Japan). Slit lamp biomicroscopy (Shinn Nippon, Tokyo, Japan) was performed to evaluate the anterior segment and the posterior segment using a 90 $\mathrm{D}$ Volk lens. For patients who did not achieve good vision with refraction, a dilated examination was performed (Mydriacyl; Alcon Inc., Fort Worth, TX, USA) for comprehensive evaluation of the lens and fundus. Intraocular pressure (IOP) was measured with air-puff tonometer (CT-60; Topcon Corp., Tokyo, Japan). For patients with IOP over $20 \mathrm{mmHg}$, Goldmann tonometry was performed to confirm the air-puff tonometry readings (Haag-Streit AG, Köniz, Switzerland).

To ensure consistency, survey staff were trained, periodically monitored and the equipment was calibrated regularly. All data collection sheets were pretested.

After the ophthalmic exam, patients diagnosed with cataract or pseudophakia with posterior capsule opacification (PCO) were referred to the HCFMB for further examination, YAG (yttrium aluminum garnet) laser or surgery and an appointment was scheduled. The municipalities provided transportation to the hospital on the day of the appointment.

At the hospital, the patient underwent another ophthalmic examination. Biometry was performed using the IOLMaster 500 (Carl Zeiss Meditec, Jena, Germany) and IOL calculations targeted emmetropia in all eyes. In eyes with dense cataracts that precluded optical biometry, the

Table 1 Characteristics of the municipalities served by the Ophthalmic Mobile Unit in 2014

\begin{tabular}{|c|c|c|c|c|c|c|}
\hline & $\begin{array}{l}\text { Total patient } \\
\text { referred n (\%) }\end{array}$ & Inhabitants n & Per capita income (R\$) & $\mathrm{M}-\mathrm{HDI}$ & $\begin{array}{l}\text { Distance to } \\
\text { the Hospital }(\mathrm{km})\end{array}$ & $\begin{array}{l}\text { Number of } \\
\text { ophthalmologists n }\end{array}$ \\
\hline Agudos & $42(7.0)$ & 34524 & 627.75 & 0.745 & 75.3 & $\mathrm{a}$ \\
\hline Barra Bonita & 99 (16.5) & 35246 & 1056.38 & 0.788 & 60.0 & 4 \\
\hline Boracéia & $41(6.8)$ & 4268 & 708.05 & 0.754 & 106.0 & a \\
\hline Brotas & $57(9.5)$ & 21580 & 807.88 & 0.817 & 92.3 & 1 \\
\hline Conchas & $27(4.5)$ & 16288 & 830.35 & 0.736 & 56.8 & 1 \\
\hline Dois Córregos & $13(2.2)$ & 24761 & 896.77 & 0.725 & 81.3 & 1 \\
\hline lacanga & $30(5.0)$ & 10013 & 758.67 & 0.779 & 150.2 & 2 \\
\hline Igaraçu do Tietê & $81(13.5)$ & 23362 & 650.03 & 0.727 & 53.3 & 1 \\
\hline Macatuba & $50(8.3)$ & 16259 & 1065.29 & 0.777 & 68.8 & 1 \\
\hline Óleo & $19(3.2)$ & 2673 & 788.27 & 0.761 & 133.3 & 2 \\
\hline Piramboia & $19(3.2)$ & 5653 & 549.16 & 0.681 & 44.2 & a \\
\hline Promissão & $102(17.0)$ & 35674 & 714.65 & 0.724 & 217.0 & a \\
\hline Taquarituba & $20(3.3)$ & 23163 & 721.89 & 0.741 & 137.4 & 1 \\
\hline
\end{tabular}

${ }^{\mathrm{a}}$ Information not provided by municipalities

$\mathrm{n}=$ number 
axial length was measured with an ultrasonic biometer (SP-1000AP; Sonoptek, Beijing, China) and the IOL power was calculated with the IOLMaster.

Patients underwent phacoemulsification or extracapsular cataract extraction (ECCE) based on surgeon preference. All patients underwent IOL implantation.

\section{Statistical analysis}

To analyze demographics and outcomes after treatment, the data obtained at the OMU visit were transferred to an Excel spreadsheet (Microsoft Corp., Redmond, WA, USA). The electronic medical records from the hospital were used to collect data on the diagnosis, surgical procedure and postoperative outcome and transferred to an Excel spreadsheet.

National data were consulted to determine possible barriers for evaluation in this study relating to patient adherence to the proposed treatment. The socioeconomic and demographic data of the assisted municipalities, such as Human Development Index (HDI), per capita income and number of inhabitants, were obtained from the Instituto Brasileiro de Geografia e Estatística - 2010 (IBGE) [10]. Data on the infrastructure of the ophthalmic service of the participating municipalities were collected using a standardized questionnaire, answered by the official representative of Public Health Care for the municipality.

Data analysis was performed with SPSS 22.0 software (IBM Corp., Armonk, NY, USA). The frequency, mean and standard deviation were calculated. Normally distributed data were analyzed by the Kolmogorov-Smirnov and Shapiro-Wilk tests. Statistical significance was indicated by $p<0.05$.

\section{Results}

During the study period, 600 patients from 13 participating municipalities were diagnosed with cataract or PCO and referred to the HCFMB. The mean age of the patients was $68.8 \pm 10.3$ years, of which 374 (62.3\%) were female, 46 (7.7\%) were blind and 202 (33.7\%) were visually impaired (Table 2 ).

Table 2 General characteristics of the six hundred individuals referred to the reference hospital in 2014

\begin{tabular}{ll}
\hline Age (years) & $68.8 \pm 10.3^{\mathrm{a}}$ \\
\hline Best Corrected Visual Acuity (logMAR) & $0.60 \pm 0.53^{\mathrm{a}}$ \\
Gender & \\
Female & $374(62.3)$ \\
Male & $226(37.7)$ \\
Blindness & $46(7.7)$ \\
Visual Impairment & $202(33.7)$ \\
Attended to the reference center & $254(42.3)$ \\
\hline
\end{tabular}

${ }^{a}$ mean \pm standard deviation $\mathrm{n}(\%)$
Two hundred and fifty-four (42.3\%) patients presented for scheduled care. Presentation to the referral hospital varied between $16 \%$ to $63 \%$ among the municipalities. Younger patients had a statistically greater tendency to present to the referral hospital $(67.4 \pm 11.3$ years vs. $70.0 \pm 9.1$ years, $p=0.004$ ) (Fig. 1 ), with no statistical influence of gender $(p>0.05)$. Attendance was statistically associated with visual impairment $(p=0.000)$ but not blindness $(p>0.05)$ (Table 3$)$.

Of the 254 patients who attended the hospital, 144 (56.7\%) underwent surgery in at least one eye, $56(22.0 \%)$ did not undergo surgery due other ophthalmic comorbidities or because the patient refused surgery, 40 (15.7\%) were pseudophakic with PCO that required YAG capsulotomy, and 14 (5.5\%) had milder lens opacities and reasonable VA with spectacle correction and remained under observation.

YAG capsulotomy was performed in 65 eyes of 40 patients, resulting in a statistically significant improvement in VA from $0.93 \pm 0.73 \log$ MAR before capsulotomy vs 0.25 $\pm 0.46 \log$ MAR after capsulotomy, $p<0.000$ ). Prior to YAG laser treatment there were four (10.0\%) blind patients and $11(27.5 \%)$ visually impaired patients. After YAG capsulotomy there was a statistically significant reduction in the number of blind patients to zero and visually impaired patients to $2(2.0 \%)(p<0.000$, both comparisons).

Of the 56 patients who did not undergo surgery, 27 (48.2\% of those who did not undergo surgery and $10.7 \%$ of all patients) had surgery postponed due to mild lens opacity, 17 (30.4) were lost to follow-up before surgery and $9(16.1 \%)$ refused surgery.

A total of 253 surgeries were performed, of which 245 were phacoemulsification and 8 were extracapsular cataract extraction (ECCE), all with IOL implantation. There was a statistically significant increase in VA from $1.07 \pm 0.73$ logMAR (20/225 Snellen acuity) preoperatively to $0.25 \pm 0.41$ $\operatorname{logMAR}$ (20/32 Snellen acuity) at last postoperative visit $(p=0.000)$. The mean improvement is VA was $-0.86 \log$ MAR, which is equivalent to 8 lines on an early treatment of diabetic retinopathy study (ETDRS) chart.

Of the patients who underwent surgery, 37 (14.6\%) had an associated ocular comorbidity and, in 32 (12.6\%) of these patients the comorbidity caused the low VA. The most common comorbidity was, age-related macular degeneration (AMD) in 11 (33.4\%) cases. Comparison of groups with and without comorbidities justifying the low VA indicated, statistically significant differences in the preoperative VA $(1.40 \pm 0.80 \log$ MAR vs $0.83 \pm 0.70$ $\operatorname{logMAR} ; p=0.000)$ and the postoperative VA $(1.05 \pm 0.82$ logMAR vs $0.21 \pm 0.40 \log$ MAR; $p=0.000$ ).

Preoperatively $17(11.8 \%)$ patients who underwent phacoemulsification in at least one eye were classified as blind and 55 (38.2\%) were considered visually impaired. There was a statistically significant decrease after phacoemulsification to $2(1.4 \%)$ blind patients and $5(3.5 \%)$ 


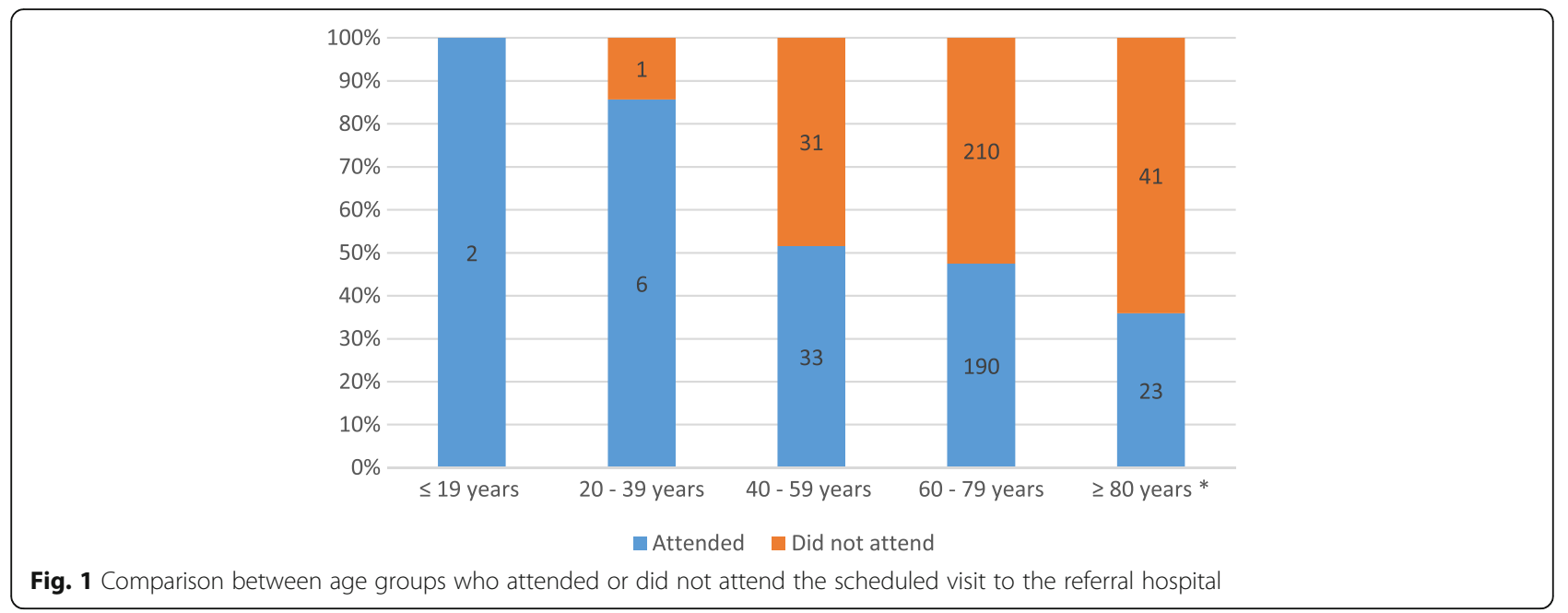

patients who were visually impairment $(p=0.000)$. Of those who remained blind or visually impaired after phacoemulsification, 4 (57.1\%) the low VA could be explained by an ocular comorbidity.

The final postoperative refraction was available for 154 (60.9\%) eyes. At the final postoperative visit the mean spherical was $-0.32 \pm 1.13 \mathrm{D}$ (range, $-3.75 \mathrm{D}$ to +2.75 $\mathrm{D}$ ), the mean cylindrical was $-1.02 \pm 1.02 \mathrm{D}$ (range $-9.00 \mathrm{D}$ to $0.00 \mathrm{D})$ and the mean spherical equivalent was $-0.83 \pm 1.11 \mathrm{D}$ (range $-3.88 \pm 2.13$ ).

There were 209 patients who underwent cataract surgery and YAG capsulotomy, of whom 21 (10.0\%) were blind and $16(7.6 \%)$ were visually impaired prior to treatment. After treatment, there was a statistically significant decrease in the number of blind patients to $2(0.9 \%)$ and $7(3.3 \%)$ remained visually impaired $(p<0.000)$.

Data on local demographics and municipal health services was provided by 9 of the 13 municipalities covered in the study. Hence data on 396 patients could be analyzed for attendance and determination of possible barriers (Table 4).

Table 3 Comparison of individuals who attended or did not present to the reference hospital in 2014

\begin{tabular}{llll}
\hline & $\begin{array}{l}\text { Attended } \\
(n=254)-n(\%)\end{array}$ & $\begin{array}{l}\text { Did not present } \\
(n=346)-n(\%)\end{array}$ & $p$ \\
\hline Age (years) & $67.4 \pm 11.3^{\mathrm{a}}$ & $70.0 \pm 9.1$ & $\mathbf{0 . 0 0 4}$ \\
$\begin{array}{l}\text { Best Visual Acuity (logMAR) } \\
\text { Gender }\end{array}$ & $0.62 \pm 0.55^{\mathrm{a}}$ & $0.59 \pm 0.52$ & 0.631 \\
$\quad$ Female & $155(61.0)$ & $219(63.3)$ & 0.571 \\
$\quad$ Male & $99(39.0)$ & $127(36.7)$ & \\
Blindness & $24(9.4)$ & $22(6.4)$ & 0.160 \\
Visual Impairment & $106(41.7)$ & $96(27.7)$ & $<\mathbf{0 . 0 0 1}$ \\
\hline
\end{tabular}

${ }^{a}$ mean \pm standard deviation

$\mathrm{n}=$ number; $p<0.05$ is statistically significant (bold values)
For patients who did not present for their scheduled visits, the municipal HDI was statistically significantly higher $(0.772 \pm 0.029$ versus $0.763 \pm 0.034, p=0.034)$, there was a statistically greater distance to the hospital $(83.2 \pm 32.9$ $\mathrm{km}$ vs $73.6 \pm 28.9 \mathrm{~km}, p=0.00$ ), a statistically higher per capita income ( $\mathrm{R} \$ 890.6 \pm 156.1$ vs $\mathrm{R} \$ 836.6 \pm 164.1, p=0.000)$ and statistically lower population $(21,923.7 \pm 9,642.4$ inhabitants vs $24,287.9 \pm 8,349.1$ inhabitants, $p=0.000$ ).

Regarding the municipality health structure, $84.2 \%$ of patients who did not present for the scheduled visit had ophthalmologists in their municipality of origin, compared to $92.3 \%$ of those who attended $(p=0.016)$. Additionally, patients who did not attend had statistically significantly more blindness prevention programs $(18.4 \%$ vs $4.8 \%, p=0.000)$, statistically better local coverage by ophthalmic surgeons $(18.4 \%$ vs $4.8 \%, p=0.000)$, statistically greater availability of ophthalmic equipment at municipal primary healthcare facilities $(50.9 \%$ vs $39.3 \%$, $p=0.022$ ) and statistically better municipal hospital services and infrastructure to perform phacoemulsification $(23.7 \%$ vs $9.5 \%, p=0.000)$.

\section{Discussion}

The outcomes of this cross-sectional study of cataract patients indicated that those who presented to the referral hospital were younger and mainly females. This observation is similar to other Brazilian studies [11-13] and is likely due to the characteristics of the Brazilian population which has a greater number of elderly women (IBGE - 2010) [10]. Although the current study reported greater female presentation to the referral hospital, there was no statistical difference between genders $(p>0.05)$.

In the current study, a relatively low number of patients (42.3\%) diagnosed with cataract (based on the OMU screening) presented to the specialized hospital for phacoemulsification or YAG capsulotomy. 
Table 4 Demographic data of 396 individuals and the municipalities of origin based on attendance in 2014

\begin{tabular}{|c|c|c|c|}
\hline & Attended $(n=168) ;(\%)$ & Did not attend ( $n=228) ; \mathrm{n}(\%)$ & $p$ \\
\hline Age (years) & $69.3 \pm 9.2^{\mathrm{a}}$ & $67.3 \pm 12.0^{a}$ & 0.081 \\
\hline Best Visual Acuity (logMAR) & $101(60.1)$ & $151(66.2)$ & 0.245 \\
\hline \multicolumn{4}{|l|}{ Gender } \\
\hline Female & $67(39.9)$ & $77(33.8)$ & \\
\hline Male & $9(5.4)$ & $21(9.2)$ & 0.181 \\
\hline Blindness & $46(27.4)$ & $59(25.9)$ & 0.818 \\
\hline $\mathrm{HDI}$ & $0.763 \pm 0.034$ & $0.770 \pm 0.029$ & 0.034 \\
\hline Distance to the specialized hospital (km) & $73.6 \pm 28.9$ & $83.2 \pm 32.9$ & 0.000 \\
\hline Per capita income (R\$) & $836.6 \pm 164.1$ & $890.6 \pm 156.1$ & 0.000 \\
\hline Inhabitants & $24287.9 \pm 8349.1$ & $21923.7 \pm 9642.4$ & 0.000 \\
\hline Patients with blindness prevention program & $8(4.8)$ & $42(18.4)$ & 0.000 \\
\hline Patients with ophthalmologist in county of origin & $155(92.3)$ & $192(84.2)$ & 0.020 \\
\hline Hospital with structure for facectomy & $16(9.5)$ & $54(23.7)$ & 0.000 \\
\hline Ophthalmic Apparatus in the basic health & $66(39.3)$ & $116(50.9)$ & 0.025 \\
\hline Cataract campaign in the last five years & $154(91.7)$ & $209(91.7)$ & 1.000 \\
\hline Total & $168(\%)$ & $228(\%)$ & \\
\hline
\end{tabular}

${ }^{a}$ mean \pm standard deviation

$\mathrm{n}=$ number; $p<0.05$ is statistically significant (bold values)

In the entire study sample, $10.0 \%$ of patients were blind and $7.6 \%$ were visually impaired at presentation. After treatment, there was a statistically significant decrease in blindness to $0.9 \%$ of patients and $3.3 \%$ of the patients were visually impaired $(p<0.000)$. Hence, despite the low patient presentation rate for referral, the treatment was effective and achieved the WHO criteria. The WHO recommends a maximum of $5.0 \%$ of patients with best corrected visual acuity less than 20/400 (blindness) after cataract surgery.

A British study of 127,658 patients reported an improvement in VA from $0.63 \log$ MAR at baseline to 0.16 $\pm 0.30 \log$ MAR after cataract surgery [8]. The VA outcomes of the current study are lower than the British study [8]. The differences in outcomes between studies are like because the British study was performed in a developed country, on a larger sample size and with earlier diagnosis. In the current study, many patients had associated ocular comorbidity that resulted in the low VA at final visit. However, the postoperative VA in patients without comorbidities in the current study was similar to the British study [8]. A recent study from São Paulo, Brazil reported a decrease from $17.6 \%$ blind patients and $23.5 \%$ visually impaired at baseline, to $5.9 \%$ and $11.8 \%$ respectively, after cataract surgery [14]. The VA outcomes from the current study are well within or exceed the range reported from other developing countries. For example, a study of cataract surgery in a rural province in Laos reported 9.5\% blind and $44.3 \%$ visually impaired postoperatively [15]. In Nigeria, 58.5\% remained blind and $16.1 \%$ remained visually impaired after surgery [16]. In Nepal, $8.0 \%$ of patients remained blind and 22.0\% remained visually impaired after surgery [17]. In Pakistan, $36.8 \%$ remained blind and $22.0 \%$ remained visually impaired [18]. The poorer VA outcomes at final postoperative visit from some of the other developing countries are likely due to the uncertain surgical conditions, often treating cases where biometry was difficult to perform, or patients were aphakic. Additionally, in some of the other developing countries standard cataract surgery techniques may not be possible the surgeons may need to improvise based on the surgical environment [19, 20]. However, in the current study cataract surgery was performed in a specialized tertiary hospital with good infrastructure with the option of IOL implantation in all patients which explains the good postoperative outcomes.

The number of surgeries, the quality of surgery and the final VA are all factors for achieving the goal of Vision 2020. Access to healthcare services is another barrier despite the strategy of approaching patients in their hometown using an OMU and detecting individuals who require surgery. For example, despite these initiatives, only $42.3 \%$ of the screened patients presented to the specialized hospital in the current study.

Our analysis of the social, economic and demographic characteristics and the health structure of the municipalities indicated that greater distance from the hospital, with higher HDI, higher per capita income and a lower municipal population were most unlikely to present to the referral hospital. These characteristics can be considered the barriers to 
treatment of cataracts in Sao Paolo State, Brazil. Interestingly the same barriers were reported in a rural region of China [21] and in central Ethiopia [22]. The factors "higher per capita income" and "higher HDI" differ from other studies, which described insufficient family income and an underdeveloped population as important barriers [21-23]. Perhaps patients with higher per capita income are able to undergo treatment in their hometown or elsewhere, bearing the expenses of the procedure. This observation may explain the lack of presentation to the referral hospital. Other factors that contribute to the low presentation rate for ophthalmic surgeries are, comorbidities, fear of the operation or of becoming blind postoperatively $[4,14]$.

There are an average 62 ophthalmologists per 1 million inhabitants in Latin America and this number is increasing. Therefore, there are an adequate number of ophthalmologists for coverage of cataract surgery [24]. However, the number of ophthalmologists that perform cataract surgery and how many surgeries each ophthalmologist performs remains unknown. Unlike a previous study [24], we found that the majority of patients who did not present to the referral hospital had a higher number of ophthalmologists in their hometown. Despite the unfavorable presentation, patients who did not attend can have their cataracts addressed in their own municipalities. These municipalities may have an adequate number of ophthalmologists, surgeons and hospital infrastructure for cataract surgery.

There are some limitations to the present study, including the lack of data on the best-corrected VA for all patients and that the barriers were not analyzed individually. Separate analyses of the barriers were not performed because we collected generalized data regarding the study population. However, there is a relative paucity of data from studies evaluating a Brazilian sample with an OMU. Hence, the outcomes of the current study provide data that can be used to allocate adequate resources and develop public healthcare initiatives.

The outcomes of the current study indicate that the elimination of cataract as a cause of blindness and/or visual impairment in Brazil requires greater coordination between the municipality and the regional tertiary hospital to ensure greater uptake of surgery.

\section{Conclusion}

Less than half of the patients diagnosed with cataract in municipalities using an OMU actually presented to a specialized hospital for treatment despite referral. However, the outcome of phacoemulsification was encouraging, resulting in a significant reduction of blind and visually impaired patients.

The main barrier to attendance were advanced age, greater distance to the specialized hospital and municipalities with lower populations. However, the presence of blindness prevention programs, ophthalmic surgeons, available ophthalmic equipment at healthcare centers and hospital with the resources to perform phacoemulsification may be factors that reduce adherence to appointments at a specialized hospital.

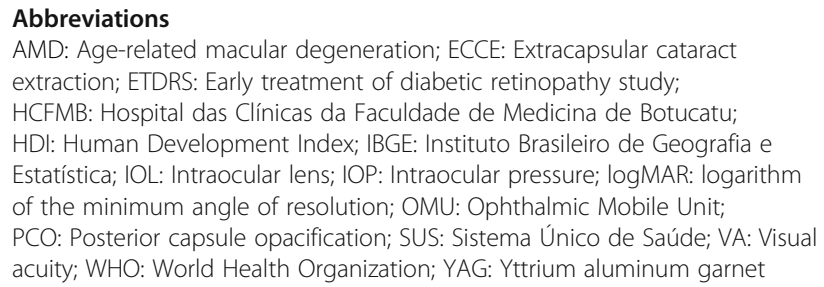

AMD: Age-related macular degeneration; ECCE: Extracapsular cataract extraction; ETDRS: Early treatment of diabetic retinopathy study; HCFMB: Hospital das Clínicas da Faculdade de Medicina de Botucatu; HDI: Human Development Index; IBGE: Instituto Brasileiro de Geografia e Estatística; IOL: Intraocular lens; IOP: Intraocular pressure; logMAR: logarithm of the minimum angle of resolution; OMU: Ophthalmic Mobile Unit; PCO: Posterior capsule opacification; SUS: Sistema Único de Saúde; VA: Visual acuity; WHO: World Health Organization; YAG: Yttrium aluminum garnet

\section{Acknowledgements \\ None. \\ Funding \\ None.}

Availability of data and materials

Data were analyzed in ophthalmology department, faculty of medicine, universidade estudual paulista - UNESP, Brazil. The datasets used and/or analyzed during the current study are available from the corresponding author on reasonable request.

\section{Authors' contributions}

GAF was the main writer and data analyzer. LFC and MFR realized the data collection. ACLR and SAS concepted and corrected the paper and suggested changes. RK collaborated with the data analysis and english spelling. All authors read and approved the final manuscript.

\section{Ethics approval and consent to participate}

The study was approved by faculty of medicine ethical committee, Universidade Estudual Paulista - UNESP, Brazil. We obtained written informed consent from al participants.

\section{Consent for publication}

Not applicable

\section{Competing interests}

The authors declare that they have no competing interests.

\section{Publisher's Note}

Springer Nature remains neutral with regard to jurisdictional claims in published maps and institutional affiliations.

Received: 4 July 2017 Accepted: 28 November 2017 Published online: 22 December 2017

\section{References}

1. Allen D, Vasavada A. Cataract and surgery for cataract. Br J Ophthalmol. 2006;333(7559):128-32

2. Pascolini D, Mariotti SP. Global estimates of visual impairment: 2010. Br J Ophthalmol. 2012;96(5):614-8.

3. Foster A. Cataract and "Vision 2020-the right to sight" initiative. Br J Ophthalmol. 2001;85(6):635-7.

4. Lewallen $S$, Courtright P. Recognising and reducing barriers to cataract surgery. Community Eye Health. 2000;13(34):20-1.

5. Kara-Júnior N, Dellapi R Jr. Espíndola RFd. Dificuldades de acesso ao tratamento de pacientes com indicação de cirurgia de catarata nos Sistemas de Saúde Público e Privado. Arq Bras Oftalmol. 2011;74:323-5.

6. Araújo Filho A, Salomão SR, Berezovsky A, Cinoto RW, Morales PHÁ, Santos FRG, et al. Prevalence of visual impairment, blindness, ocular disorders and cataract surgery outcomes in low-income elderly from a metropolitan region of São Paulo - Brazil. Arq Bras Oftalmol. 2008;71:246-53. 
7. Salomão SR, Mitsuhiro MRKH, Belfort R Jr. Visual impairment and blindness: an overview of prevalence and causes in Brazil. An Acad Bras Ciênc. 2009;81:539-49.

8. Day AC, Donachie PH, Sparrow JM, Johnston RL, Royal College of Ophthalmologists' National Ophthalmology D. The Royal College of Ophthalmologists' National Ophthalmology Database study of cataract surgery: report 1, visual outcomes and complications. Eye (Lond). 2015;29(4):552-60.

9. Tabin G, Chen M, Espandar L. Cataract surgery for the developing world. Curr Opin Ophthalmol. 2008;19(1):55-9.

10. Instituto Brasileiro de Geografia e Estatística. Censo Demográfico 2010. Avalible from: http://www.ibge.gov.br/home/estatistica/populacao/ censo2010/. [Last accessed on: $29 \mathrm{dez} 2016$ ]

11. Gomes BAF, Biancardi AL, Fonseca Netto C, FFP G, HVD MJ. Perfil socioeconômico e epidemiológico dos pacientes submetidos à cirurgia de catarata em um hospital universitário. Rev Bras Oftalm. 2008:67:220-5.

12. LMPD S, Muccioli C, Belfort $R \mathrm{Jr}$. Perfil socioeconômico e satisfação dos pacientes atendidos no mutirão de catarata do Instituto da Visão - UNIFESP. Arq Bras Oftalmol. 2004;67:737-44.

13. Ventura LO, Brandt CT. Projeto Mutirão de Catarata em centro de referência oftalmológico, em Pernambuco: perfil, grau de satisfação e benefício visual do usuário. Arq Bras Oftalmol. 2004;67:231-5.

14. Mitsuhiro MH, Berezovsky A, Belfort R Jr, Ellwein LB, Salomao SR. Uptake, Barriers and Outcomes in the Follow-up of Patients Referred for Free-ofCost Cataract Surgery in the Sao Paulo Eye Study. Ophthalmic Epidemiol. 2015;22(4):253-9.

15. Shields MK, Casson RJ, Muecke J, Laosern S, Louangsouksa P, Vannavong S, et al. Intermediate-Term Cataract Surgery Outcomes from Rural Provinces in Lao People's Democratic Republic. Ophthalmic Epidemiol. 2015;22(4):260-5.

16. Odugbo OP, Mpyet CD, Chiroma MR, Aboje AO. Cataract blindness, surgical coverage, outcome, and barriers to uptake of cataract services in Plateau State. Nigeria. Middle East Afr J Ophthalmol. 2012;19(3):282-8.

17. Thapa SS, Khanal S, Paudyal I, Twyana SN, Ruit S, van Rens GH. Outcomes of cataract surgery: a population-based developing world study in the Bhaktapur district. Nepal. Clin Experiment Ophthalmol. 2011;39(9):851-7.

18. Bourne R, Dineen B, Jadoon Z, Lee PS, Khan A, Johnson GJ, et al. Outcomes of cataract surgery in Pakistan: results from The Pakistan National Blindness and Visual Impairment Survey. Br J Ophthalmol. 2007:91(4):420-6.

19. Venkatesh R, Muralikrishnan R, Balent LC, Prakash SK, Prajna NV. Outcomes of high volume cataract surgeries in a developing country. Br J Ophthalmol. 2005;89(9):1079-83.

20. Lindfield R, Vishwanath K, Ngounou F, Khanna RC. The challenges in improving outcome of cataract surgery in low and middle income countries. Indian J Ophthalmol. 2012;60(5):464-9.

21. Zhang XJ, Jhanji V, Leung CK, Li EY, Liu Y, Zheng C, et al. Barriers for poor cataract surgery uptake among patients with operable cataract in a program of outreach screening and low-cost surgery in rural China. Ophthalmic Epidemiol. 2014;21(3):153-60.

22. Mehari ZA, Zewedu RT, Gulilat FB. Barriers to cataract surgical uptake in central ethiopia. Middle East Afr J Ophthalmol. 2013;20(3):229-33.

23. Dhaliwal U, Gupta SK. Barriers to the uptake of cataract surgery in patients presenting to a hospital. Indian J Ophthalmol. 2007;55(2):133-6.

24. Batlle JF, Lansingh VC, Silva JC, Eckert KA, Resnikoff S. The cataract situation in Latin America: barriers to cataract surgery. Am J Ophthalmol. 2014;158(2): 242-250 e1.

\section{Submit your next manuscript to BioMed Central and we will help you at every step:}

- We accept pre-submission inquiries

- Our selector tool helps you to find the most relevant journal

- We provide round the clock customer support

- Convenient online submission

- Thorough peer review

- Inclusion in PubMed and all major indexing services

- Maximum visibility for your research

Submit your manuscript at www.biomedcentral.com/submit

CBiomed Central 